\title{
A Subpopulation of Neurons in the Medial Prefrontal Cortex Encodes Emotional Learning with Burst and Frequency Codes through a Dopamine $\mathrm{D}_{4}$ Receptor-Dependent Basolateral Amygdala Input
}

\author{
Steven R. Laviolette, ${ }^{1}$ Witold J. Lipski, ${ }^{1}$ and Anthony A. Grace ${ }^{1,2,3}$ \\ Departments of ${ }^{1}$ Neuroscience, ${ }^{2}$ Psychiatry, and ${ }^{3}$ Psychology, University of Pittsburgh, Pittsburgh, Pennsylvania 15260
}

\begin{abstract}
The basolateral nucleus of the amygdala (BLA) and medial prefrontal cortex (mPFC) are involved importantly in the processing and encoding of emotionally salient learned associations. Here, we examined the possible role of the $\mathrm{mPFC}$ in the acquisition and encoding of emotional associative learning at the behavioral and single-neuron level. A subpopulation of neurons in the mPFC that received monosynaptic and orthodromic inputs from the BLA demonstrated strong associative responding to odors paired previously with footshock by increasing spontaneous activity and bursting activity. This occurred specifically in response to postconditioning presentations of the footshock-paired odors but not to odors presented in the absence of footshock. In contrast, $\mathrm{mPFC}$ neurons that failed to respond to BLA stimulation showed no associative responding. Systemic or intra-mPFC blockade of dopamine (DA) $\mathrm{D}_{4}$ receptors prevented this emotional associative learning in neurons of the MPFC and blocked the expression of olfactory conditioned fear. These results demonstrate that individual neurons in the MPFC that receive a functional input from the BLA actively encode emotional learning and that this process depends on $\mathrm{DA} \mathrm{D}_{4}$ receptor stimulation in the mPFC.
\end{abstract}

Key words: amygdala; cortex; learning; neuron; plasticity; dopamine receptor; prefrontal cortex

\section{Introduction}

The ability to assign appropriate emotional significance to incoming sensory information and to form learned associations between emotional states and related stimuli in the environment is essential for normal cognitive functioning and behavior. The mammalian medial prefrontal cortex (mPFC) and basolateral division of the amygdala (BLA) are anatomically and functionally interconnected (Aggleton, 2000) and are critical for the processing and integration of emotionally salient sensory information and learning (Garcia et al., 1999; Milad and Quirk, 2002; Rosenkranz and Grace, 2002; Milad et al., 2004). Considerable evidence implicates the $\mathrm{MPFC}$ as being critical for the extinction (unlearning) of conditioned associations between environmental stimuli and fear-inducing events such as footshock (Milad and Quirk, 2004; Santini et al., 2004). In contrast, the BLA appears to be primarily involved in the processing and initial acquisition phase of learned fear associations (LeDoux, 2000; Nader et al., 2000; Rosenkranz and Grace, 2002). The mPFC modulates neuronal activity, sensory responses, and emotional learning within the BLA by regulating the extinction of conditioned fear and the

Received March 24, 2005; revised May 6, 2005; accepted May 14, 2005.

This work was supported by United States Public Health Service Grant DA15408 and by a Canadian Institutes of Health Research Postdoctoral Fellowship to S.R.L.

Correspondence should be addressed to Dr. Steven Laviolette at the above address. E-mail: laviolette@bns.pitt.edu.

D0I:10.1523/JNEUROSCI.1168-05.2005

Copyright $\odot 2005$ Society for Neuroscience $\quad$ 0270-6474/05/256066-10\$15.00/0 encoding of emotional learning within the BLA via descending inputs (Quirk et al., 2003; Rosenkranz and Grace, 2003; Milad et al., 2004). It is not known, however, whether neurons in the mPFC actively encode and acquire emotionally salient learned associations and, if so, how such processes may be regulated by input from the BLA.

Considerable evidence has suggested that the mPFC is involved in the processing of emotionally salient sensory information. For example, neuronal activity in the mammalian mPFC increases in response to auditory or contextual cues that predict an aversive footshock (Baeg et al., 2001) and other emotionally relevant stimuli (Ono et al., 1984; Inout et al., 1985), suggesting that information related to the expression of emotional learning is processed within the mPFC. In addition, the amygdala modulates the activity of the mPFC during fear conditioning by controlling the degree to which a conditioned auditory tone reduces spontaneous activity in the rodent mPFC (Garcia et al., 1999), whereas electrical stimulation of the $\mathrm{MPFC}$ during fear conditioning attenuates conditioned fear responses with respect to both behavior and neuronal activity in the amygdala (Rosenkranz and Grace, 2003; Milad et al., 2004). However, no previous evidence has demonstrated a role for the mPFC in the encoding and acquisition of emotionally salient learned associations.

To examine the possible role of individual mPFC neurons in the acquisition and encoding of learned emotional associations, we recorded extracellularly from single units in the mPFC of chloral hydrate $(8 \%)$-anesthetized rats during a pavlovian odor 
fear-conditioning procedure and compared firing rates and neuronal bursting parameters of these neurons before and after conditioning. We further analyzed the role of dopamine (DA) $\mathrm{D}_{4}$ receptors in the $\mathrm{mPFC}$ in the encoding and expression of emotional learning using both single-unit extracellular recordings of $\mathrm{mPFC}$ neurons and in an olfactory fear-conditioning procedure in behaving animals.

\section{Materials and Methods}

Animal preparation. All procedures were performed in accordance with the National Institutes of Health Guide for the Care and Use of Laboratory Animals and were approved by the University of Pittsburgh Institutional Animal Care and Use Committee. Male Sprague Dawley rats (275-350 g) were anesthetized with an intraperitoneal injection of $400 \mathrm{mg} / \mathrm{kg}$ of $8 \%$ chloral hydrate and placed in a stereotaxic device (David Kopf Instruments, Tujunga, CA). Subsequent supplements of choral hydrate were administered via a lateral tail vein catheter or intraperitoneally, as required. Body temperature was monitored with a rectal temperature probe (Precision Thermometer 4600; Yellow Springs Instruments, Yellow Springs, $\mathrm{OH}$ ) and maintained at $\sim 37^{\circ} \mathrm{C}$ using a heat control unit and heating pad (Fintronics, Orange, CT). Incisions were made in the scalp to expose the skull, and burr holes were drilled and the dura was removed overlying the BLA or mPFC. Coordinates for these areas were determined using the stereotaxic atlas of Paxinos and Watson (1986), as follows (in mm from bregma): BLA, anteroposterior (AP), - 3.0; lateral (L), \pm 5.0 ; ventral $(\mathrm{V}),-8.0$ from the dural surface. For the mPFC, +3.0 rostral, 0.5 lateral, and -3.4 ventral from the dural surface. For bilateral intra-mPFC guide cannulas implantation, animals were anesthetized with ketamine-xylazine and placed in a stereotaxic frame. Bilateral guide cannulas were implanted in the $\mathrm{mPFC}$ at a $15^{\circ}$ angle with the following coordinates (in mm from bregma): AP, $+2.9 ; \mathrm{L}, \pm 1.9 ; \mathrm{V},-3.0$ from the dural surface. Guide cannulas were secured with jeweler's screws and dental acrylic.

Single-unit recordings. Single-barrel electrodes were constructed using a vertical microelectrode puller (Narishige, Tokyo, Japan) and filled with $2 \%$ pontamine sky blue in $2 \mathrm{M} \mathrm{NaCl}$ (impedance measured in situ ranged between 8 and $20 \mathrm{M} \Omega$ measured at $1 \mathrm{kHz}$ ). Recording electrodes were lowered slowly into the mPFC via a hydraulic micromanipulator (Narishige). A bipolar concentric stimulating electrode (Plastics One, Roanoke, VA) was lowered into the BLA. Stimulation of the BLA was delivered using a Grass Instruments (Quincy, MA) S88 stimulator. BLA stimulation was between 100 and $800 \mu \mathrm{A}$. Signals from the recording electrode were amplified by a headstage connected to the preamplifier before being fed into a window discriminator/amplifier (Fintronics) and an audio monitor (AM5; Grass Instruments). Signals were filtered with a low cutoff of $200 \mathrm{~Hz}$ and a high cutoff of $8 \mathrm{kHz}$ and displayed on an oscilloscope (Kikusui, Yokohama, Japan). Data were simultaneously collected and monitored on-line using software developed in this laboratory (Neuroscope) and stored on computer for later off-line analysis. To isolate neurons in the MPFC that responded to BLA stimulation, electrical stimulus pulses were delivered during electrode penetration of the $\mathrm{MPFC}$ to search for units that exhibited evoked responses $(0.5 \mathrm{~Hz} ; 0.2-0.6 \mathrm{~mA}$; $0.3 \mathrm{~ms}$ duration). Evoked responses consisted of spike activity recorded from single neurons. The latency of response to BLA input was determined as the time from the beginning of the stimulus artifact to the beginning of the evoked spike. Single-unit evoked spikes were operationally defined as monosynaptic and orthodromic if they showed very little shift in latency when increasing stimulus intensity but some range (1-5 $\mathrm{ms}$ ) in latency distribution ("jitter") and failed to follow high-frequency stimulation $(>250)$, thus ruling out antidromic activation. In addition, collision tests were performed on mPFC neurons responding to BLA stimulation to verify orthodromicity. At the end of recording experiments, neuronal recording locations were marked by ejection of pontamine sky blue from the recording electrode with constant $-25 \mu \mathrm{A}$ current. A nonresponsive mPFC control neuron was defined as a spontaneously active mPFC neuron that failed to show any evoked responses to at least 100 stimulations of the BLA over a range of test currents (200-800 $\mu \mathrm{A} ; 0.5 \mathrm{~Hz} ; 0.3 \mathrm{~ms}$ duration).
Bursting analysis. We hypothesized that the spiking of mPFC neurons could be described by two separate spiking modes: regular spiking and bursting. We further hypothesized that each of these spiking modes produced a characteristic interspike interval (ISI) distribution that could be modeled by an inverse Gaussian probability density (IGPD) function (Barbieri et al., 2001). We therefore fit our collective baseline ISI histogram with a sum of two IGPDs, as follows:

$$
P\left(w_{i} \mid \mu_{b}, \lambda_{b}, \mu_{r}, \lambda_{r}\right)=f\left(w_{i} \mid \mu_{r}, \lambda_{r}\right)+f\left(w_{i} \mid \mu_{b}, \lambda_{b}\right),
$$

where

$$
f\left(w_{i} \mid \mu, \lambda\right)=\left(\frac{\lambda}{2 \pi w_{i}^{3}}\right)^{\frac{1}{2}} \exp \left\{-\frac{\lambda\left(w_{i}-\mu\right)^{2}}{2 \mu^{2} w_{i}}\right\},
$$

and $w_{i}$ is an interspike interval in the distribution; $\mu_{r}$ and $\mu_{b}$ are the expected values of the regular-mode and burst-mode ISI, respectively; and $\mu^{3} \lambda^{-1}$ describes the variance of each distribution. Fit optimization was performed in Matlab (MathWorks, Natick, MA) using a leastsquares algorithm with the following four free parameters: $\mu_{r}, \lambda_{r}, \mu_{b}, \lambda_{b}$. To determine whether bursting represented a qualitatively distinct property of mPFC neuronal activity across our conditioning modes as opposed to simply an epiphenomenon of increased firing frequency, we analyzed the firing frequency [taking the difference between baseline firing frequency and firing frequency during presentation of the conditioned stimulus (CS)] as a function of percentage of bursting (taking the difference between baseline bursting percentage and bursting frequency percentage during presentation of the CS). We then performed a linear regression analysis comparing percentage of bursting as a function of firing frequency.

Pavlovian conditioning: electrophysiological recording experiments. A conditioning procedure was performed by pairing an odor (peppermint or almond) with a footshock. This procedure was adapted from a previously described odor-conditioning procedure in anesthetized rats (Rosenkranz and Grace, 2002). The footshock was delivered by two 28 gauge needles inserted in the lateral side of the foot contralateral to the neuronal recordings. During the conditioning phase, each odor (peppermint or almond) was presented a minimum of four times, for $10 \mathrm{~s}$, with a $60 \mathrm{~s}$ delay between presentations. One odor was randomly selected to be paired with footshock. Paired odor selection was fully counterbalanced across experiments. The footshock-paired odor (CS + ) was paired with the delivery of footshock ( $5 \mathrm{~s} ; 8 \mathrm{~mA} ; 20 \mathrm{~Hz} ; 0.3 \mathrm{~ms}$ duration), which was followed by presentation of the nonpaired odor (CS-). This pairing process was performed four to six times. After this, a 2 min rest period took place before the test phase. During the test phase, the CS + odor and the CS- odor were presented for $30 \mathrm{~s}$, and neuronal activity was recorded for an additional $90 \mathrm{~s}$ period.

Drug administration. Drugs were administered either intravenously through a lateral tail vein or directly into the BLA (unilaterally) through a chematrode (Plastics One), which allows for both local drug microinfusion and electrical stimulation of the region of interest. For mPFC microinfusions, stainless steel guide cannulas (22 gauge) were implanted bilaterally into the mPFC (see Fig. $1 C$ ), and drugs were administered through a 28 gauge microinfusion injector (Plastics One). For olfactory fear-conditioning experiments in anesthetized animals, the selective dopamine $\mathrm{D}_{4}$ receptor antagonist 3-(4-chlorophenyl)-4-methyl-5-(1-(2phenylethyl)piperidin-4-yl)isoxazole hydrochloride (L-741,741; $0.08-0.8 \mathrm{mg} / \mathrm{kg}$, i.v.; Tocris Cookson, Bristol, UK) was dissolved in DMSO, which was then diluted in PBS, $\mathrm{pH}$ adjusted to 7.4, and administered intravenously $5 \mathrm{~min}$ before the start of the conditioning procedure. After a BLA-responsive mPFC neuron was isolated, baseline activity was recorded for $2 \mathrm{~min}$. After this, animals received the injection over $1 \mathrm{~min}$, and neuronal activity was recorded for an additional $2 \mathrm{~min}$ before the olfactory conditioning procedure began. Baseline firing activity of mPFC neurons was not affected by the higher dose $(0.8 \mathrm{mg} / \mathrm{kg})$ of the $\mathrm{D}_{4}$ antagonist drug (mean firing frequency before drug, $0.84 \mathrm{~Hz}$; after drug, $0.86 \mathrm{~Hz})$. One group of animals received saline $(n=11)$, whereas two additional groups received either $0.08 \mathrm{mg} / \mathrm{kg}(n=10)$ or $0.8 \mathrm{mg} / \mathrm{kg}(n=$ 12) of the antagonist. For intra-BLA muscimol experiments, muscimol 
(500 ng/0.5 $\mu$ l; Sigma, St. Louis, MO) was dissolved in PBS, pH adjusted to 7.4, and microinfused unilaterally into the BLA 2-3 min before the start of the conditioning procedure. Neuronal activity was recorded for at least $2-3$ min before and during the entire drug infusion procedure (for both intravenous and intra-BLA administration) to ensure that no changes in baseline activity were induced by the drug.

Olfactory fear conditioning in awake rats. Rats were taken from their home cages, received sham microinfusions into the mPFC, and habituated for $30 \mathrm{~min}$ in a ventilated conditioning chamber with an electric grid floor inside a sound-attenuated room. Olfactory fear conditioning took place in one of two distinct environments, counterbalanced within groups: "shock" environment A had black walls and a metallic grid shock floor, whereas shock environment B had white walls with a grid shock floor. Testing $24 \mathrm{~h}$ later took place in one of two alternate environments, in which animals had not previously received electric shock, counterbalanced within groups: test environment A had black walls and a black Plexiglas floor, whereas test environment $B$ had white walls with a black Plexiglas floor. On day 1 (habituation phase), animals were habituated to a random combination of shock environment $\mathrm{A}$ or $\mathrm{B}$ and test environment $\mathrm{A}$ or B in a counterbalanced order for $30 \mathrm{~min}$ in each environment. On day 2 (conditioning phase), animals were returned to the conditioning room. Bilateral microinfusions into the $\mathrm{mPFC}$ were then performed of either saline vehicle $(n=6)$ or the selective $\mathrm{DA} \mathrm{D}_{4}$ antagonist L-741,741 ( 5 or $50 \mathrm{ng} / 0.5 \mu \mathrm{l}$; both groups, $n=7$ ), and the rat was placed in the previously assigned shock environment. During the conditioning phase, one of the odors (almond or peppermint) was presented to the animal for $19 \mathrm{~s}$, and a footshock was then delivered $(0.8 \mathrm{~mA})$ for $1 \mathrm{~s}$. Two minutes later, the alternate odor was presented for $20 \mathrm{~s}$ (CS-) in the absence of footshock. This conditioning cycle was repeated five times. On the following day (test phase), rats were returned to the test room and placed in the previously assigned test environment. Before odor presentation, the rat was allowed to explore the environment for $1 \mathrm{~min}$, during which time baseline levels of freezing and exploratory behavior were observed. Odors (CS+ or CS-) were then presented for 5 min each to the animal in a counterbalanced order, and the amount of time freezing was recorded. Freezing was defined as complete immobility with the exception of respiratory-related movement. To control for possible statedependency effects of the intra-mPFC dopamine $\mathrm{D}_{4}$ receptor antagonist in the olfactory fear-conditioning experiment in awake animals, we performed a separate experiment, wherein animals received intra-mPFC $\mathrm{L}-741,741(50 \mathrm{ng} / \mu \mathrm{l})$ both during the conditioning phase (see above) and also immediately before the testing phase to determine whether the presence of the drug in the mPFC would influence expression of olfactory fear conditioning. We also analyzed exploratory behavior in response to presentations of CS + or CS - odors, as described previously (Rosenkranz and Grace, 2003). Exploratory behavior was scored as follows, and a score was assigned for every min of each of the 5 min during the odor presentations: 0 , no locomotion; 1 , ambulation across one side of the testing chamber; 2 , ambulation across two sides; 3 , exploration of the full perimeter of the testing chamber; and 4, exploration of the center and entire perimeter of the test chamber.

Footshock sensitivity analysis. To determine whether our pharmacological manipulations (intra-mPFC or intravenous $\mathrm{D}_{4}$ antagonist experiments) induced alterations in sensitivity to footshock, we rigorously monitored behavioral and neuronal responses to these manipulations before and after drug administration. For intra-mPFC experiments, we performed a separate experiment, wherein animals received either bilateral intra-mPFC saline (control) or the $\mathrm{D}_{4}$ antagonist (L-741,741; 50 $\mathrm{ng} / 0.5 \mu \mathrm{l})$ and were placed in either a black or white conditioning box (see above description) with a footshock grid floor. We presented footshocks $(0.8 \mathrm{~mA} ; 1 \mathrm{~s})$ over four times following the same time course of presentation as in the olfactory fear-conditioning experiments (see previous section) and measured sensitivity to footshock over four separate variables: (1) frequency of ultrasonic, $22 \mathrm{kHz}$ vocalizations in response to the footshock [a reliable index of footshock sensitivity (Tonoue et al., 1986; Antoniadis and McDonald, 1999)], (2) number of jumps in response to footshock; (3) amount of defecation (in grams) during footshock session; (4) percentage of time freezing in the 20 s postfootshock interval. All of these behavioral indices of footshock sensitivity have been reported as reliable indicators of fear reactivity to the presentation of a footshock stimulus (Antoniadis and McDonald, 1999). Ultrasonic 22 $\mathrm{kHz}$ vocalizations were amplified with an ultrasound Bat detector (Pettersson Elektronik AB, Tallbacksvagen, Sweden) placed inside the conditioning chamber and monitored with headphones by the observer. For electrophysiological experiments under choral hydrate anesthesia, we compared the number of neuronal spikes in response to footshock presentations during the conditioning phase of the experiment between saline control animals and animals pretreated with intravenous L-741,741 (0.8 mg/kg).

Histology. Extracellular recording sites in the mPFC, electrical stimulation sites in the BLA, and bilateral intra-MPFC guide cannulas placements were all verified histologically. At the end of the experiments, rats were deeply anesthetized, decapitated, and the brains were removed and fixed in $10 \%$ formalin solution for a minimum of $24 \mathrm{~h}$. Brains were cryoprotected with $25 \%$ sucrose in $0.1 \mathrm{~m}$ phosphate buffer, then frozen and sectioned with a cryostat. Mounted sections were then stained with cresyl violet. Recording sites were identified with pontamine sky blue spots. The stimulation site was determined from the ventral-most point of the stimulating electrode track identified under light microscopy. Bilateral $\mathrm{mPFC}$ microinfusion locations were determined by the location of the injector tip.

Statistics. Data were analyzed with one-, two-, or three-way ANOVA where appropriate or $t$ tests. Post hoc analyses were performed with Newman-Keuls tests.

\section{Results}

\section{Electrophysiological recordings}

We isolated mPFC neurons (Fig. 1A) that responded orthodromically and presumably monosynaptically with evoked spikes to discrete electrical stimulation of the BLA (100-600 $\mu \mathrm{A} ; 0.5$ $\mathrm{Hz}$; 0.3 ms pulses) (Fig. $1 B$ ) or from control neurons that failed to respond to BLA stimulation (see Materials and Methods). The average \pm SEM response latency for all tested $\mathrm{mPFC}$ neurons receiving BLA input $(n=57)$ was $21.3 \pm 1.51 \mathrm{~ms}$. Initial studies revealed that the average \pm SEM firing frequency (recorded over a 2 min baseline) for mPFC neurons responding to BLA stimulation was $1.21 \pm 0.41 \mathrm{~Hz}$, whereas that for nonresponding $\mathrm{mPFC}$ neurons $(n=25)$ was $1.15 \pm 0.37 \mathrm{~Hz}$. Established criteria for $\mathrm{mPFC}$ neuronal subtypes classifies these $\mathrm{mPFC}$ neurons into two classes: regular-spiking neurons with firing rates $<5 \mathrm{~Hz}$ that are believed to correspond to pyramidal neurons versus fast-spiking neurons with firing rates $>10 \mathrm{~Hz}$ and shorter duration waveforms that are believed to correspond to interneurons (Degenetais et al., 2002; Jackson et al., 2004). In the present study, we conditioned BLA-responsive $\mathrm{mPFC}$ neurons corresponding to these preestablished criteria for pyramidal neurons. Fast-spiking mPFC interneurons $(>10 \mathrm{~Hz})$ that responded to BLA stimulation were rarely encountered. After recording the baseline activity of isolated $\mathrm{mPFC}$ neurons, rats were presented with specific odors (either peppermint or almond in a counterbalanced order) that were paired either with footshock $(\mathrm{CS}+)$ or the absence of footshock $(\mathrm{CS}-)$. Using this olfactory fear-conditioning paradigm with in vivo intracellular recording, we have shown previously that neurons in the rat lateral nucleus of the amygdala demonstrate reliable conditioning to odors paired previously with footshock and significantly increase their postsynaptic potentials and neuronal excitability selectively in response to the presentation of the CS+ odor (Rosenkranz and Grace, 2002, 2003). This conditioned responding in neurons of the amygdala occurs regardless of whether animals are conditioned while awake or under anesthesia (Rosenkranz and Grace, 2003). In addition, considerable evidence demonstrates that associative learning can take place in both humans and other animal species 

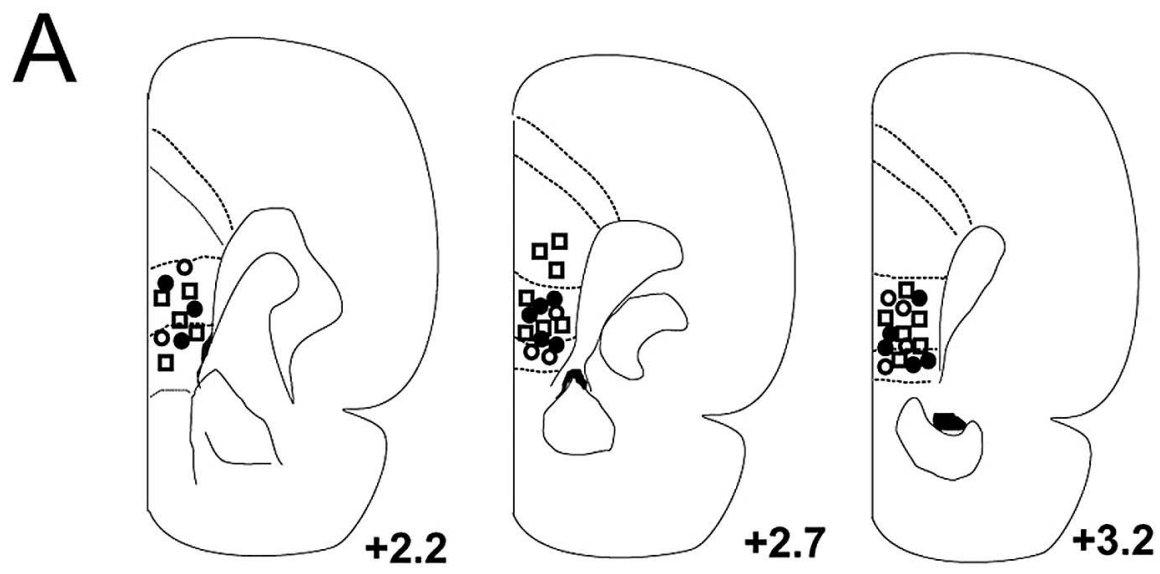

B
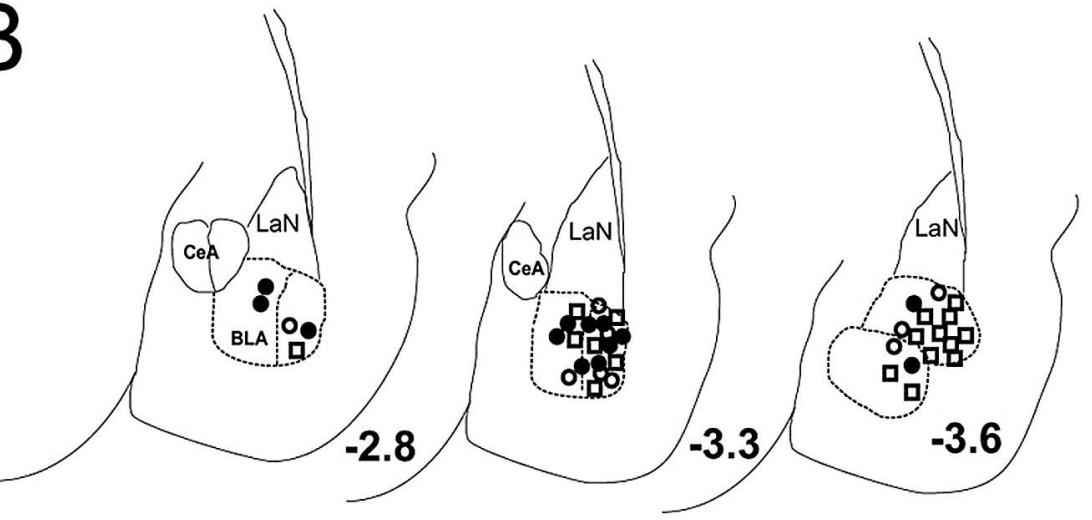

Figure 1. Histological analysis of intra-mPFC recording sites and BLA stimulation sites. For clarity, only representative, nonoverlapping samples are shown to illustrate the general anatomical distribution of these recording and stimulation sites. $A$, For the $\mathrm{mPFC}$, black circles, systemic $D_{4}$ antagonist $(0.8 \mathrm{mg} / \mathrm{kg} ; n=12)$; open circles, non-BLA-responsive mPFC neurons $(n=9)$; open squares, BLA-responsive mPFC neurons ( $n=18)$. $\boldsymbol{B}$, For the BLA, black circles, systemic $\mathrm{D}_{4}$ antagonist $(0.8 \mathrm{mg} / \mathrm{kg} ; n=12)$; open circles, non-BLA-responsive mPFC neurons $(n=9)$; open squares, BLA-responsive mPFC neurons $(n=18)$. CeA, Central nucleus of the amygdala; LaN, lateral nucleus of the amygdala.

under anesthesia, in the absence of conscious awareness (Rosenkranz and Grace, 2002; Deeprose et al., 2004; Wong et al., 2004).

\section{Pavlovian associative learning in neurons of the mPFC}

Isolated mPFC neurons that received orthodromic, monosynaptic input from the BLA demonstrated strong associative learning to odors paired previously with footshock. This was expressed by significant increases in the number of spontaneous spikes relative to baseline levels in response to postconditioning presentations of odors paired previously with footshock $(\mathrm{CS}+)$ but not to odors that were paired with the absence of footshock (CS-) (Fig. $2 A, B)$. Neurons in the mPFC showed significantly increased responding to footshock-paired odors not only at testing (expression) but also during the conditioning phase of the associativelearning procedure over trials (Fig. 2C). Analysis revealed a significant effect of conditioning on neuronal responses to the $\mathrm{CS}+$ odor relative to the $\mathrm{CS}-$ odor as a function of trial $\left(F_{(4,209)}=3.51 ; p<0.01\right)$. Indeed, BLA-responsive mPFC neurons $(n=24)$ showed significantly greater responding to CS+ odor versus the CS - odor by the second learning trial $(p<0.05)$ and at all subsequent conditioning trials $(p<0.05)$ (Fig. $2 C$ ). Comparing the activity of these same BLA-responsive mPFC neurons during the preconditioning baseline activity phase to the postconditioning CS + presentation phase and the CS - presentation phase revealed that BLA-responsive $\mathrm{mPFC}$ neurons showed a significant effect of testing phase (baseline vs CS + vs CS - presentations; $\left.F_{(2,83)}=17.1 ; p<0.0001\right)$ on spike number. Neuronal activity was increased significantly above baseline only to presentations of the CS+ $(p<0.001)$, not to the CS $-(p>0.05)$ (Fig. 3A). In a separate group of animals $(n=12)$, we examined the functional role of the BLA in emotional learning in BLA-responsive neurons of the $\mathrm{mPFC}$ by pharmacologically inactivating the BLA with muscimol, a $\mathrm{GABA}_{\mathrm{A}}$ receptor agonist $(500 \mathrm{ng} / 0.5 \mu \mathrm{l})$, before the olfactory-conditioning procedure. Inactivation of the BLA prevented the expression of associative learning in BLAresponsive neurons (Fig. 3A) and no effect of test phase on neuronal activity was present in these neurons $(n=12)\left(F_{(11,35)}\right.$ $=0.01 ; p>0.05)$. Associative neuronal responses were absent also in non-BLAresponsive control neurons $\left(n=23 ; F_{(2,53)}\right.$ $=0.11 ; p>0.05)$ (Fig. $3 B)$. We performed a subsequent analysis of $\mathrm{MPFC}$ neuronal responses specifically during the $10 \mathrm{~s}$ time periods, wherein rats were first exposed to the CS+ or CS- odors during the conditioning phase (before either odor had been paired with footshock) and the postconditioning responses to the $\mathrm{CS}+$ or $\mathrm{CS}-$ odors during the first $10 \mathrm{~s}$ of odor presentation during the test phase. Comparing preconditioning odor responses and postconditioning odor responses revealed a significant effect of test phase (before or after) on mPFC neuronal responses $\left(F_{(3,87)}\right.$ $=15.8 ; p<0.0001)$, with BLA-responsive mPFC neurons $(n=24)$ showing a significant firing increase specifically in response to the presentation of the CS+ $(p<0.01)$ but not to the CS $-(p>0.05)$ (Fig. $3 C)$. Pharmacological inactivation of the BLA with muscimol also blocked associative neuronal responding in BLA-responsive neurons during these odor presentation time epochs $\left(n=12 ; F_{(23,47)}=\right.$ $2.6 ; p>0.05$ ) (Fig. $3 C$ ). Similarly, non-BLA-responsive $\mathrm{mPFC}$ neurons $(n=23)$ showed no differences in neuronal responding between odor presentation epochs $\left(F_{(3,71)}=1.2 ; p>0.05\right)$ (Fig. $\left.3 D\right)$. We observed no difference in $\mathrm{MPFC}$ neurons localized to either the infralimbic or prelimbic regions (Fig. 1A) in terms of associative learning or bursting activity. That is, neurons localized to either the infralimbic or prelimbic cortical regions were just as likely to display associative learning or increased bursting in response to presentations of the CS+.

Neurons in the mPFC increase bursting activity specifically in response to emotionally salient conditioned odors

Prefrontal cortical neurons generally display two types of firing patterns: a regular, tonic firing mode and a bursting firing mode, wherein trains of spikes are discharged in discrete bursting events (Connors and Gutnick, 1990; Baeg et al., 2001). Cortical neuronal bursting has been hypothesized to represent the processing of reward-related learning cues, memory encoding as well as decision-making, and behavioral flexibility (Ono et al., 1984; Inout et al., 1985; Schultz and Dickinson, 2000). To quantify the 


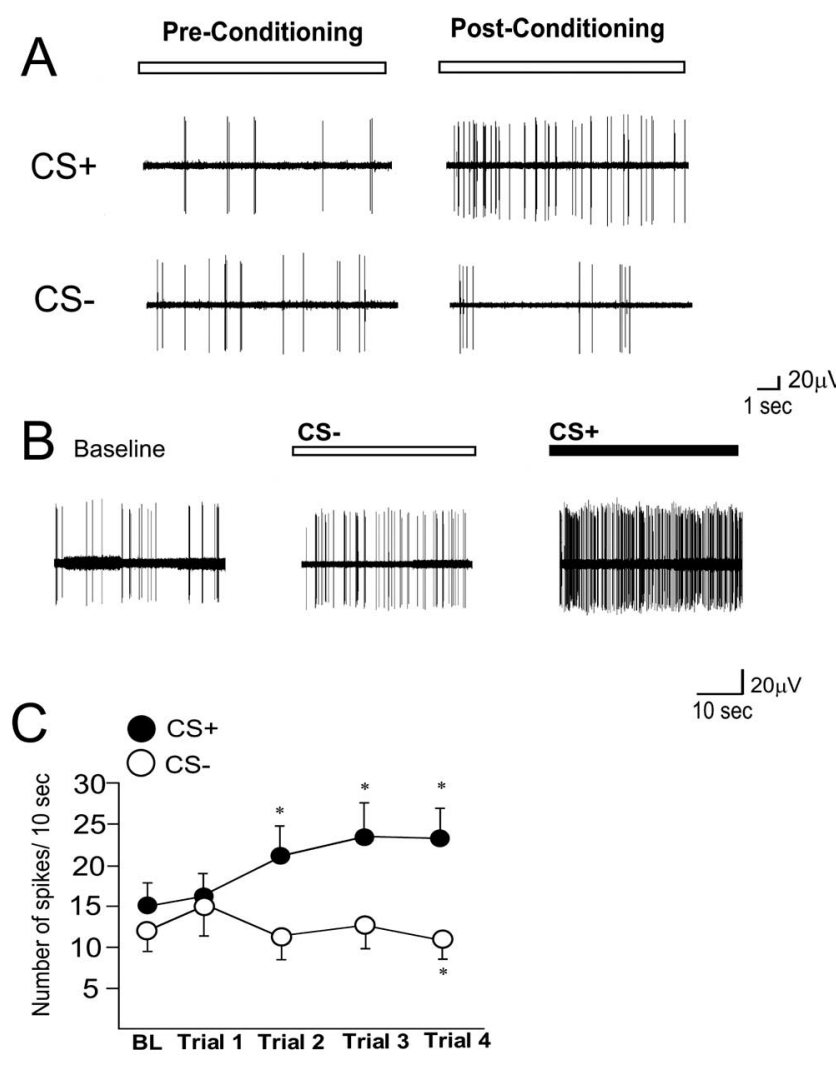

Figure 2. Neuronal responses of BLA-responsive $\mathrm{MPFC}$ neurons to test presentations of the $C S$ + versus $C S$ - olfactory stimuli. $A$, Neuronal activity traces of a single $\mathrm{mPF}$ (neuron showing preconditioning (before footshock pairings) versus postconditioning neuronal responses to $\mathrm{CS}+$ versus $C S$ - odors over $10 \mathrm{~S}$ of odor presentation. A strong increase in neuronal activity is observed in this neuron, specifically in response to the $C S+$ odor after conditioning. $\boldsymbol{B}$, Neuronal activity traces of a single $\mathrm{MPFC}$ neuron comparing preconditioning baseline activity to postconditioning spontaneous activity to presentations of the $C S$ - versus $C S+$ odors (see Materials and Methods). Open bars represent presentation of the $(S$ - odor, whereas the black bar represents the presentation of the $\mathrm{CS}+$ odor for this and all subsequent graphs. A dramatic increase in neuronal activity is observed specifically in response to the $C S+$ odor after conditioning. C, Mean number of spontaneous spikes from BLA-responsive neurons ( $n=24)$ during the 10 s conditioning trials over time (see Materials and Methods). BLA-responsive mPFC neurons show significant increases in activity in response to the $(S+$ odor by the second conditioning trial and all subsequent trials ( ${ }^{*} p<0.05$ for this and all subsequent graphs). In contrast, these neurons showed a significant decrease from trial 1 responding relative to trial 4 responding to the CS - . BL, Baseline. Error bars represent SEM.

level of bursting exhibited between neurons, the distribution of ISIs pooled from 54 baseline PFC neurons was modeled with the sum of two IGPDs. Least-squares fit optimization of four free parameters resulted in a good fit to the data, with a narrow IGPD $\left(\right.$ IGPD $_{\mathrm{b}}$ ) centered on low ISIs (expectation value, $\mu_{b}=24.4 \mathrm{~ms}$; variance, $\mu_{b}{ }^{3} \lambda_{b}{ }^{-1}=55.6 \mathrm{~ms}^{2}$ ) and a broad IGPD shifted to higher ISIs (expectation value, $\mu_{r}=167 \mathrm{~ms}$; variance, $\mu_{r}{ }^{3} \lambda_{r}{ }^{-1}=$ $16500 \mathrm{~ms}^{2}$ ). This fit was consistent with our hypothesis that our population of PFC neurons fired in one of two modes: highfrequency bursting and lower-frequency regular spiking. Although it was not possible to completely discriminate these two spiking modes solely on the basis of firing frequency, we chose the median ISI in the $\operatorname{IGPD}_{\mathrm{b}}$ (45 ms) as an arbitrary threshold between bursting and regular spiking. Based on our model, two spikes with ISI below this threshold had an $83 \%$ chance of constituting a burst. We used this 45 ms cutoff point as the criterion for all subsequent burst analyses. After establishing these criteria for burst identification, the computer algorithm was verified by examining which sets of spike trains recorded from mPFC neurons in vivo were accurately flagged as burst events according to this $45 \mathrm{~ms}$ criterion. In all cases, only spike trains that could be identified visually as burst events were flagged by the computer as bursts. Furthermore, this was not simply a function of firing frequency. For example, neurons could be identified that exhibited substantial differences in ISI distribution and burst firing percentages despite similarities in baseline firing rates (Fig. $4 A, B$ ).

We analyzed the bursting parameters of mPFC neurons in response to presentation of the $\mathrm{CS}+$ and $\mathrm{CS}-$ olfactory stimuli presentations. BLA-responsive and -nonresponsive neurons in the $\mathrm{mPFC}$ displayed some bursting activity in the baseline (preconditioning) phase but more typically exhibited nonbursting, regular spike firing patterns (Fig. $4 B, C$ ). However, these same neurons demonstrated a significant increase in the percentage of burst events specifically in response to the presentation of the $\mathrm{CS}+$ odor (Fig. $4 \mathrm{~B}, \mathrm{C}$ ). The percentage of spike events occurring as bursts are presented for a single BLA-responsive mPFC neuron across baseline, CS+, and CS- in Figure 4C. Comparing the percentage of spikes occurring in burst events over the 2 min odor test period revealed a significant main effect of test phase and percentage of spike events occurring in bursts $\left(F_{(24,74)}=18.6\right.$; $p<0.0001)$. Post hoc analysis revealed that BLA-responsive mPFC neurons $(n=25)$ showed significantly greater bursting relative to baseline in response to the CS+ presentation $(p<$ $0.01)$ but not in response to the CS $-(p>0.05)$ (Fig. 5A). Pharmacological inactivation of the BLA with muscimol (500 ng/0.5 $\mu \mathrm{l})$ blocked this associative bursting response in BLA-responsive neurons $(n=13)$, and no difference was observed in the percentage of bursting events across test phases in these neurons $\left(F_{(12,38)}=0.01 ; p>0.05\right)$ (Fig. $\left.5 A\right)$. Non-BLA-responsive mPFC neurons did not show any significant increases in bursting activity in response to $\mathrm{CS}+$ presentations or $\mathrm{CS}-$ presentations relative to baseline levels $\left(F_{(19,55)}=1.44 ; p>0.05\right)$ (Fig. $\left.5 B\right)$. BLAresponsive neurons $(n=24)$ also demonstrated a significant increase in the number of spikes per burst event specifically in response to the CS + odor presentation relative to CS - and baseline levels $\left(F_{(24,74)}=14.2 ; p<0.0001\right)$ (Fig. 5C). Post hoc analysis revealed that BLA-responsive $\mathrm{MPFC}$ neurons showed significantly greater spikes per burst event in response to the $\mathrm{CS}+(p<$ $0.01)$ relative to $\mathrm{CS}-$ and baseline levels $(p>0.05)$. Inactivation of the BLA with muscimol (500 $\mathrm{ng} / 0.5 \mu \mathrm{l})$ prevented this effect in BLA-responsive mPFC neurons $\left(n=13 ; F_{(12,38)}=1.5 ; p>0.05\right)$ (Fig. $5 C$ ). Non-BLA-responsive control neurons $(n=17)$ also failed to show any differences in the number of spikes per burst event across the test phases $\left(F_{(19,59)}=0.64 ; p>0.05\right)$ (Fig. $\left.5 D\right)$. To determine whether bursting represented a qualitatively distinct property of mPFC neuronal activity across our conditioning modes as opposed to simply an epiphenomenon of increased firing frequency, we analyzed the firing frequency (taking the difference between baseline firing frequency and firing frequency during presentation of the $\mathrm{CS}+$ ) as a function of percentage of bursting (taking the difference between baseline bursting percentage and bursting frequency percentage during presentation of the CS+) (Fig. 5E). We performed a linear regression analysis comparing percentage of bursting as a function of firing frequency and found that there was no significant correlation between firing frequency and the percentage of neuronal bursting occurring at baseline levels versus the presentation of the CS+ $\left(r^{2}=0.002 ; p>0.05\right)$ (Fig. $\left.5 E\right)$. Thus, bursting in neurons of $\mathrm{mPFC}$ can occur independent of increases in firing rate, suggesting that the increase in bursting in response to the presentation of the CS+ (Fig. $5 A-D$ ) is not simply an epiphenomenon of in- 
A

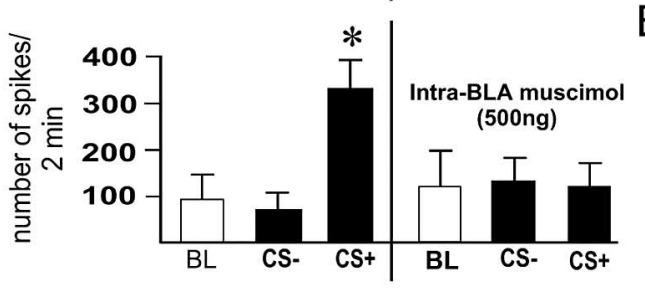

C

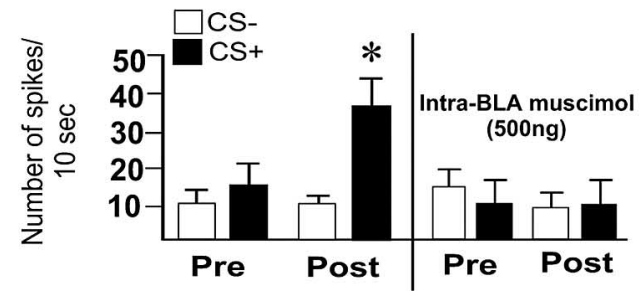

Non-Responsive
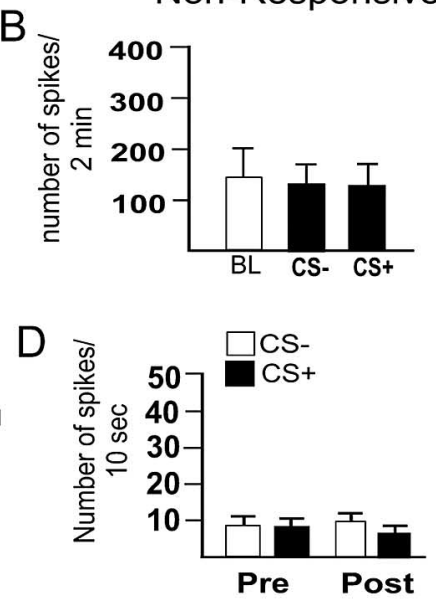

Figure 3. $\quad \boldsymbol{A}$, Number of spontaneous spikes in response to $\mathrm{CS}+$ versus $\mathrm{CS}-$ odor presentation tests (120 s) relative to preconditioning baseline activity (120s) shows a significant increase in responding specifically to the $\mathrm{CS}+$ odor $(p<0.001)$. Intra-BLA muscimol (see Materials and Methods) prevents associative learning in BLA-responsive mPFC neurons $\left({ }^{*} p<0.05\right)$. $\boldsymbol{B}$, In non-BLA-responsive control neurons, no differences in neuronal activity are observed between baseline and $(S+$ versus CS - odor presentations ( $p>0.05$ ). C, Comparing the 10 s neuronal responses to $C S+$ or $C S$ - odors before conditioning (Pre) versus after conditioning (Post) in BLA-responsive $\mathrm{mPFC}$ neurons revealed associative responding specifically to the $\mathrm{CS}+$ odor $(p<0.01)$. Intra-BLA muscimol (500 ng) prevented this associative learning $\left({ }^{*} p<0.05\right)$. D , In nonresponsive control neurons, neuronal responding does not differ between preconditioning (Pre) CS + versus $C S$ - odor presentations relative to postconditioning (Post) responses $(p>0.05)$. BL, Baseline. Error bars represent SEM.

creased firing frequency to CS+ presentations (Fig. $3 A-D)$. We also compared mean intraburst intervals across conditions and found no significant difference between intraburst intervals across baseline, CS + , or CS - conditions $\left(F_{(24,74)}=0.007 ; p>\right.$ 0.05 ) (Fig. $5 F$ ), demonstrating that whereas the percentage of burst events increases specifically in response to the CS + presentation, the firing frequency within each burst remains essentially constant.

\section{Emotional learning in neurons of the MPFC depends on signaling through a dopamine $\mathrm{D}_{4}$ receptor substrate}

Dopamine signaling is involved in emotional and sensory processing in both the amygdala and the mPFC (Rosenkranz and Grace, 2002; Pezze et al., 2003; Pezze and Feldon, 2004). We examined the possible role of the $\mathrm{DA} \mathrm{D}_{4}$ receptor subtype in the $\mathrm{mPFC}$ in our olfactory associative learning paradigm for several reasons. First, this specific subtype is found in high concentrations in the mammalian prefrontal cortex (Mrzljak et al., 1996; Wedzony et al., 2000). Second, $\mathrm{mPFC}_{4}$ receptors are involved importantly in the expression of fear-related behaviors in rodents (Shah et al., 2004). Third, the $\mathrm{D}_{4}$ receptor is critical for DAmediated potentiation of $\mathrm{mPFC}$ neuronal excitability (Ceci et al., 1999) and is linked to various intracellular signaling cascades such as the CAM-kinase II and glutamatergic signaling in the mPFC, both of which are critical for synaptic plasticity and other learning- and memory-related molecular processes ( $\mathrm{Gu}$ and Yan, 2004).

We examined the possible role of the $\mathrm{DA}_{4}$ receptor in the mediation of emotional learning in neurons of the $\mathrm{MPFC}$ with both extracellular recordings and in an olfactory fearconditioning procedure in behaving animals. For extracellular recording experiments, animals received an intravenous injection of L-741,741 $(0.08-0.8 \mathrm{mg} / \mathrm{kg})$, a competitive and specific antagonist of the $\mathrm{DA}_{4}$ receptor subtype, before the olfactory conditioning procedure. Comparing the activity of BLA- responsive $\mathrm{mPFC}$ neurons during the preconditioning baseline activity phase to the postconditioning $\mathrm{CS}+$ presentation phase and the CS - presentation phase revealed a significant interaction between group and treatment $\left(F_{(11,107)}=7.8 ; p<0.0001\right)$. Post hoc analysis revealed that whereas both saline control and the lower dose of L-741,741 groups showed significantly increased neuronal responding in response to the CS+ odor relative to the CS- odor and baseline activity $(p<0.01)$, mPFC neurons in animals receiving the higher dose of antagonist $(0.8 \mathrm{mg} / \mathrm{kg})$ displayed no associative responding in response to the presentation of the CS+ odor (Fig. $6 A)$. We performed a subsequent analysis of $\mathrm{mPFC}$ neuronal responses specifically during the $10 \mathrm{~s}$ time periods, wherein rats were first exposed to the CS+ or CSodors during the conditioning phase (before either odor had been paired with footshock) and the postconditioning responses to the CS+ or CS - odors during the first $10 \mathrm{~s}$ of presentation. Comparing preconditioning odor responses and postconditioning odor responses revealed a significant interaction between group, treatment, and time (before or after conditioning) on mPFC neuronal responses $\left(F_{(2,131)}=5.1 ; p<0.01\right)$. Post hoc analysis revealed that BLA-responsive $\mathrm{mPFC}$ neurons in the control and lower dose $(0.08 \mathrm{mg} / \mathrm{kg})$ groups displayed significant firing increases specifically in response to the presentation of the CS+ $(p<0.05)$ but not to the CS - (Fig. 6B). In contrast, BLAresponsive $\mathrm{mPFC}$ neurons showed no differences in neuronal responding across test phases in animals receiving the higher dose of the $\mathrm{D}_{4}$ antagonist $(p>0.05)$ (Fig. $\left.6 \mathrm{~B}\right)$. Analysis of bursting activity revealed that $\mathrm{mPFC}$ neurons in both control and the lower-dose L-741,741 groups showed significantly higher percentages of bursting activity during the odor presentation test, specifically in response to the $\mathrm{CS}+$. Analysis revealed a significant effect of condition on percentage of spikes occurring in burst events $\left(F_{(2,101)}=5.02 ; p<0.01\right)$ (Fig. 6C), and post hoc analysis revealed that whereas control and lower-dose L-741,741 groups displayed significantly increased bursting specifically in response to the CS+ odor presentation $(p<0.05)$, mPFC neurons in animals receiving the higher dose of the antagonist showed no increase in responding in response to the CS+ presentation, relative to baseline and CS - responses (Fig. 6C). Comparing the number of spikes per bursting event across these groups revealed a significant interaction between group and treatment $\left(F_{(11,107)}=\right.$ 4.04; $p<0.01$ ) (Fig. 6D). Post hoc analysis revealed that whereas the average number of spikes per bursting event was significantly increased in both control and lower-dose antagonist groups specifically in response to the CS + presentation $(p<0.05)$, this effect was absent in animals receiving the higher dose of L-741,741 (0.8 mg/kg; $p>0.05$ ) (Fig. 6D). Thus, activation of DA $\mathrm{D}_{4}$ receptors is critical for the encoding and expression of emotional learning in neurons of the mPFC that receive functional input from the BLA. For electrophysiological conditioning experiments under anesthesia, analysis of neuronal responses over trials in saline control versus L-741,741 (0.8 mg/kg, i.v.)pretreated animals demonstrated no significant differences at any 

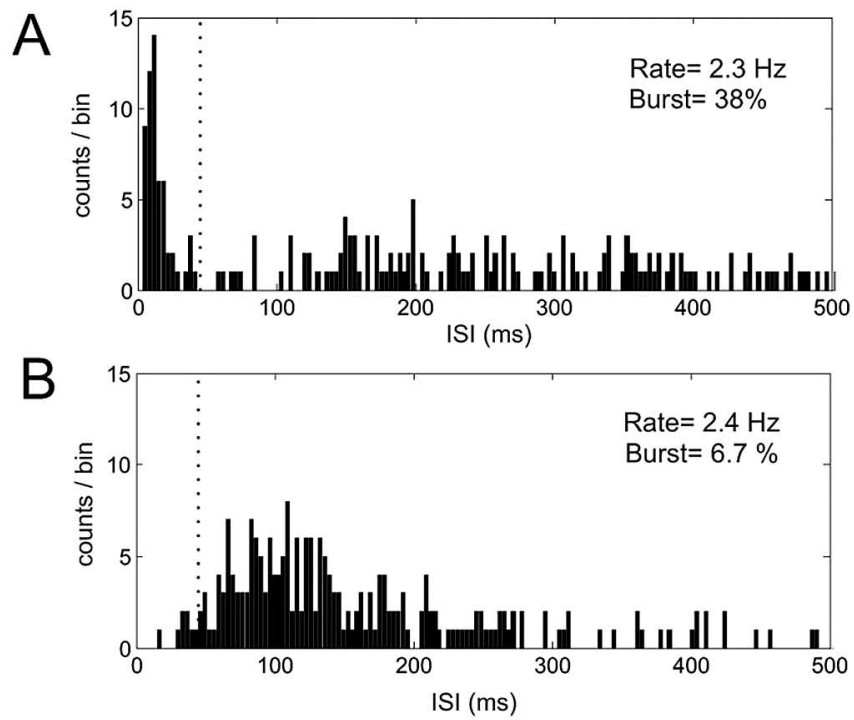

C

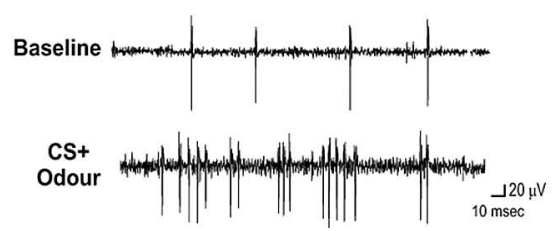

D

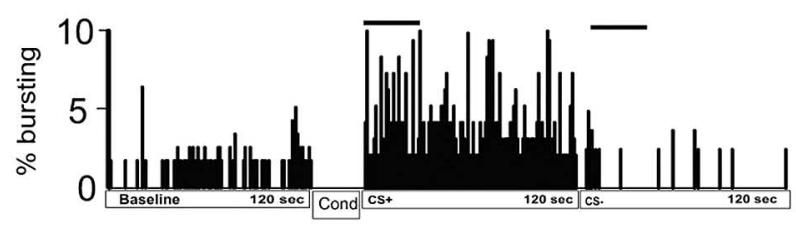

Figure 4. Degree of burst firing was independent of firing frequency in $\mathrm{mPFC}$ neurons. $A$ and $B$ show ISI histograms obtained from representative PFC neurons exhibiting marked differences in firing pattern despite firing at a similar frequency. $A$, An example of a neuron showing a high degree of bursting (37\%), as can be observed from the peak in the ISI histogram at short ISIs. $\boldsymbol{B}$, An example of a neuron showing primarily an irregular pattern of spike discharge with few burst events, as evidenced by the more symmetrical ISI distribution and a low degree of bursting (6.7\%). The dotted line marks the cutoff for burst ISIs ( $45 \mathrm{~ms}$ ). C, Neuronal activity traces from a single mPFC, BLA-responsive neuron recorded during the first $5 \mathrm{~s}$ of preconditioning baseline activity and the first $5 \mathrm{~s}$ of $\mathrm{CS}+$ odor presentation after conditioning illustrate typical baseline, nonbursting activity responding pattern versus postconditioning bursting response to the $\mathrm{CS}+$ odor presentation. This neuron demonstrated no bursting activity in response to the CSpresentation. $\boldsymbol{D}$, Percentage of spiking events occurring in bursts for a single, BLA-responsive $\mathrm{mPFC}$ neuron comparing the baseline bursting level relative to the postconditioning responses to the presentation of the $C S+$ odor versus the $C S$ - odor. Typically, BLA-responsive neurons showed a dramatic increase in bursting specifically in response to the $C S$ + versus the $C S$ - odor relative to baseline. Cond, Conditioning.

time in neuronal responding to footshock presentation during conditioning $\left(F_{(9,79)}=0.34 ; p>0.05\right)$ (Fig. $\left.6 E\right)$. In addition, we compared baseline neuronal activity before and after administration of the effective dose of L-741,741 (measured before the start of olfactory conditioning) and found no significant difference between these conditions (data not shown) $\left(t_{(7)}=1.3 ; p>0.05\right)$. In addition, systemic administration of the $\mathrm{D}_{4}$ antagonist $(0.8 \mathrm{mg} / \mathrm{kg}$, i.v. $)$ had no effect on spontaneous baseline neuronal responses or to odor neuronal responses to preconditioning presentations $(p>0.05)$ (Fig. $6 A, B)$, indicating that $\mathrm{mPFC}$ neurons were still responsive to olfactory stimulation in the presence of the DA antagonist.
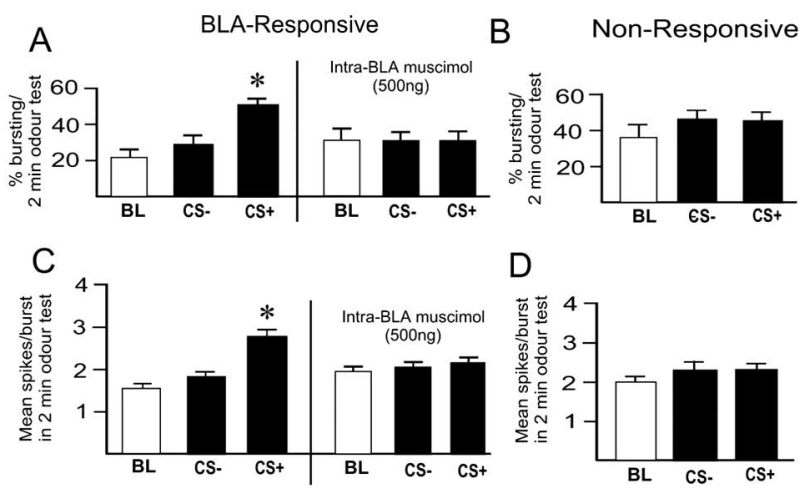

D
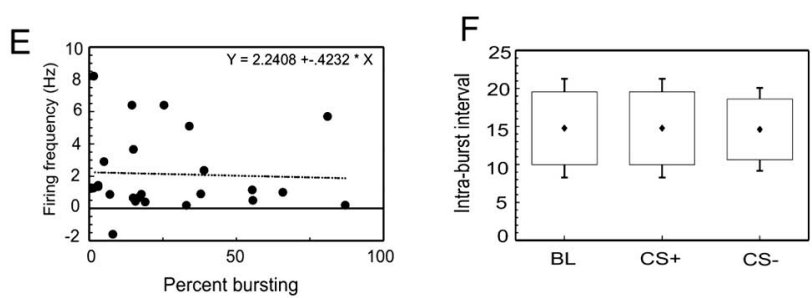

Figure 5. Analysis of neuronal bursting activity in BLA-responsive and -nonresponsive mPFC neurons during associative conditioning. $A$, Percent bursting for BLA-responsive mPFC neurons in response to $C S$ + versus $C S$ - odor presentation tests $(120 \mathrm{~s})$ relative to preconditioning baseline activity (120 s) shows a significant increase in percentage of bursting events specifically to the $C S+$ odor $(p<0.01)$. Intra-BLA muscimol $(500 \mathrm{ng})$ prevents associative bursting responses in BLA-responsive $\mathrm{mPFC}$ neurons $(p<0.05) . \boldsymbol{B}$, In non-BLA-responsive mPFC neurons, no associative responding to $C S$ + versus $C S$ - odor presentations relative to baseline was observed with respect to the percentage of bursting events during the test phases $(p>0.05)$. $C$, In BLA-responsive mPFC neurons, the mean number of spikes per bursting event was significantly increased specifically in response to the $C S+$ odor presentation $(p<0.01)$. Intra-BLA muscimol ( $500 \mathrm{ng}$ ) prevented this associative increase in the number of spikes per burst event $(p<0.05)$. $\boldsymbol{D}$, In non-BLA-responsive $\mathrm{MPFC}$ neurons, no increase in the number of spikes per burst event was observed in response to the $C S$ + versus $C S$ - presentation relative to baseline. $\boldsymbol{E}$, Analysis of the relationship between firing frequency and the percentage of spike events occurring in bursts reveals no significant correlation between $\mathrm{MPFC}$ neuronal firing frequency and percentage of burst events. The difference between baseline firing frequency and $\mathrm{CS}+$ firing frequency is plotted as a function of the difference between baseline percentage of bursting and $C S+$ percentage of bursting in the same neurons. $F$, Comparing mean intraburst interstimulus intervals across baseline, $C S+$, and $C S$ - conditions reveals no significant difference across conditions ( $p>0.05)$. BL, Baseline. Error bars represent SEM.

\section{Olfactory fear conditioning in awake animals}

We next performed an olfactory fear conditioning experiment in awake, behaving animals. Bilateral guide cannulas were implanted in the mPFC (Fig. 7A), and microinfusions of the same $\mathrm{DA} \mathrm{D}_{4}$ antagonist (L-741,741; 5 and $\left.50 \mathrm{ng} / \mu \mathrm{l}\right)$ were performed immediately before the olfactory fear-conditioning procedure (see Materials and Methods). Twenty-four hours after conditioning, we measured the percentage of time animals spent freezing in response to the presentation of the CS+ or CS- odors, respectively. Analysis revealed a significant interaction between group and treatment $\left(F_{(2,37)}=12.1 ; p<0.001\right)$ on times spent freezing to the CS+ versus CS - odor presentations (Fig. 7B). Post hoc analysis revealed that whereas saline control $(n=6)$ and animals receiving the $5 \mathrm{ng}$ dose $(n=7)$ displayed significantly greater time freezing specifically in response to the presentation of the CS + odor $(p<0.05)$, animals receiving a higher dose of intramPFC L-741,741 (50 ng) did not demonstrate significantly greater freezing behavior to the $\mathrm{CS}+$ odor relative to the CSodor at testing $(p>0.05)$ (Fig. $7 A)$. We ran an additional experiment $(n=6)$, wherein animals received intra-mPFC L-741,741 immediately before the test phase. Animals tested in the presence of intra-mPFC L-741,741 (50 ng) displayed no difference in 
A
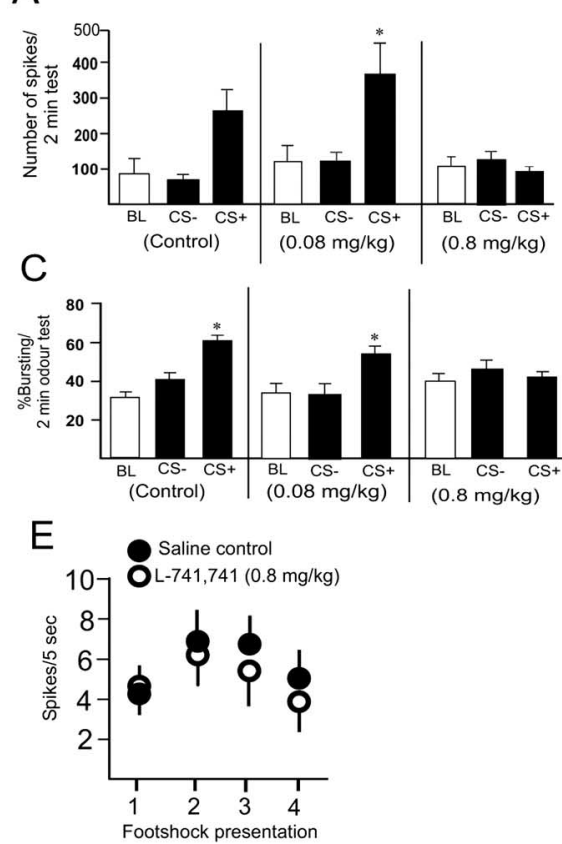

Figure 6. The effects of systemic administration of the $D A D_{4}$ receptor antagonist $L-741,741(0.08-0.8 \mathrm{mg} / \mathrm{kg}$, i.v. $)$ on olfactory associative learning in BLA-responsive neurons of the mPFC. A-D, A subthreshold $(0.08 \mathrm{mg} / \mathrm{kg}$, i.v.) and suprathreshold $\left(0.8 \mathrm{mg} / \mathrm{kg}\right.$, i.v.) was used $\left({ }^{*} p<0.05\right)$. $\boldsymbol{A}$, Comparison of the spontaneous neuronal activity produced in response to presentations of $C S+$ versus $C S$ - versus baseline activity during the 2 min odor tests revealed that saline control animals $(n=11)$ demonstrated strong associative learning in response to $C S+$ odor presentations relative to $C S-$ and baseline activity $(p<0.01)$. The lower dose of $\mathrm{L}-741,741(0.08 \mathrm{mg} / \mathrm{kg})$ did not block this associative neuronal learning $(p<0.01)$, whereas the higher dose $(0.8 \mathrm{mg} / \mathrm{kg})$ prevented olfactory associative learning in mPFC neurons $(p>0.05)$. $\boldsymbol{B}$, Comparison of the 10 s neuronal responses to $\mathrm{CS}+$ or $\mathrm{CS}$ - odors before conditioning (Pre) versus after conditioning (Post) in BLA-responsive mPFC neurons revealed associative responses specifically to the $C S+$ odor after conditioning in both the saline control group $(n=11)$ and the lower $\mathrm{L}-741,741$ dose $(0.08 \mathrm{mg} / \mathrm{kg})$ group $(n=10)$. However, a higher dose of L-741,741 $(0.8 \mathrm{mg} / \mathrm{kg} ; n=12)$ completely blocked this neuronal associative responding. C, Percentage of bursting of BLA-responsive mPFC neurons in response to CS + versus CS - odor presentation tests $(120 \mathrm{~s})$ relative to preconditioning baseline activity $(120 \mathrm{~s})$ shows a significant increase in percentage of bursting specifically to the $C S+$ odor in the saline control group $(n=11)$ and the lower-dose group of L-741,741 $(0.08 \mathrm{mg} / \mathrm{kg}$; $n=10)$, whereas the higher dose $(0.8 \mathrm{mg} / \mathrm{kg} ; n=12)$ completely blocked this effect. $\boldsymbol{D}$, In BLA-responsive mPFC neurons, the mean number of spikes per burst event was significantly increased specifically in response to the $C S+$ odor presentation in the saline control group $(p<0.01 ; n=11)$ and in the lower-dose $L-741,741$ group $(p<0.01 ; n=10)$. However, this associative responding was blocked in animals receiving a higher dose of $L-741,741(0.8 \mathrm{mg} / \mathrm{kg} ; n=12 ; p>0.05)$. $E$, Comparing neuronal responding in response to footshock presentation during the conditioning trials between saline control and animals pretreated with the effective dose of $L-741,741(0.8 \mathrm{mg} / \mathrm{kg}$, i.v.) revealed no significant differences in neuronal responses to footshock during any of the conditioning trials ( $p>0.05)$. BL, Baseline. Error bars represent SEM.

dose of the intra-mPFC DA D $\mathrm{D}_{4}$ antagonist (50 ng/0.5 $\mu \mathrm{l}$ ) pretreatment, we analyzed neuronal and behavioral sensitivity to footshock under these experimental conditions (see Materials and Methods). In olfactory fear-conditioning experiments in awake animals, no significant differences were observed between saline control or intra-mPFC L-741,741-treated animals in the number of evoked $22 \mathrm{kHz}$ vocalizations $\left(t_{(5)}=0.67 ; p>0.05\right)$ (Fig. $\left.7 D\right)$ in response to footshock. No significant differences were observed in the amount of defecation (in grams) between groups in response to footshock $\left(t_{(5)}=0.68 ; p>\right.$ $0.05)$ (Fig. 7E). No significant differences across trials in the number of footshockevoked jumps were observed between groups $\left(F_{(9,39)}=1.0 ; p>0.05\right)($ Fig. $7 F)$, and no significant differences were observed across trials in the percentage of time spent freezing in the immediate $20 \mathrm{~s}$ interval after footshock between groups $\left(F_{(9,39)}=0.02\right.$; $p>0.05$ ) (Fig. 7G). These results, combined with the data showing no influence of systemic L-741,741 (0.8 mg/kg, i.v.) on baseline responses to footshock (Fig. 6A,B) or footshock (Fig. $6 E$ ), suggest that blockade of DA $\mathrm{D}_{4}$ receptors with effective doses of either intra-mPFC or systemic L-741,741 does not produce any appreciable decrease in odor or footshock sensitivity at the behavioral or neuronal levels.

\section{Discussion}

Although previous evidence has suggested an important role for the mPFC in the encoding of extinction of learned emotional associations, our results demonstrate that single neurons in the mPFC can actively encode and express emotional learning. Interestingly, the processing of emotional learning in the mPFC depends critically on a functional input from the BLA; only a subpopulation of $\mathrm{mPFC}$ neurons receiving

freezing in response to $\mathrm{CS}+$ or $\mathrm{CS}-$ presentations $\left(t_{(5)}=1.8 ; p>\right.$ 0.05 ) (Fig. $7 B$ ), demonstrating that the observed block in olfactory associative learning with an effective dose of the intra-mPFC $\mathrm{D}_{4}$ antagonist was not caused by any state dependency effects. Comparing exploratory behavior scores across groups in response to $\mathrm{CS}+$ or CS - presentations revealed a significant main effect of treatment on exploratory behavior $\left(F_{(2,59)}=22.3 ; p<0.0001\right)$ during testing (Fig. 7C). Post hoc analysis revealed that whereas both control and the $5 \mathrm{ng}$ dose group displayed significantly lower exploratory behavior in response to the presentation of the CS+ relative to CS$(p<0.05)$, this effect was absent in the animals receiving the $50 \mathrm{ng}$ dose of intra-mPFC L-741,741 (Fig. 7C). In addition, animals tested under the intra-mPFC $\mathrm{D}_{4}$ antagonist cue displayed no attenuation in exploratory behavior in response to presentations of the CS+ or CS $-\left(F_{(5,17)}=0.5 ; p>0.05\right)($ Fig. $7 C)$.

\section{$D_{4}$ receptor blockade and footshock sensitivity}

To examine whether the observed behavioral effects might be explained by possible sensory deficits induced by the effective a direct input from the BLA demonstrate emotional associative learning, and this was blocked by inactivation of the BLA. This suggests that in addition to the role of cortical structures in the gating and modulation of emotional learning in the amygdala through a descending pathway from the cortex to the amygdala (Rosenkranz and Grace, 2003; Milad et al., 2004), the neuronal encoding of emotionally salient associations also occurs through a functional ascending pathway from the amygdala to the cortex. This may suggest that emotional learning takes place in a distributed neural network involving the MPFC-amygdala pathway.

One possibility is that the initial association between the conditioned stimulus and its emotional salience takes place in the amygdala, and this learned association is then transferred to the mPFC for consolidation. This is supported by the finding that pharmacological inactivation of the BLA before conditioning prevented the encoding and expression of emotional associative learning in the mPFC. Nevertheless, the emotional learning we observed in single neurons of the mPFC occurred very rapidly 
A
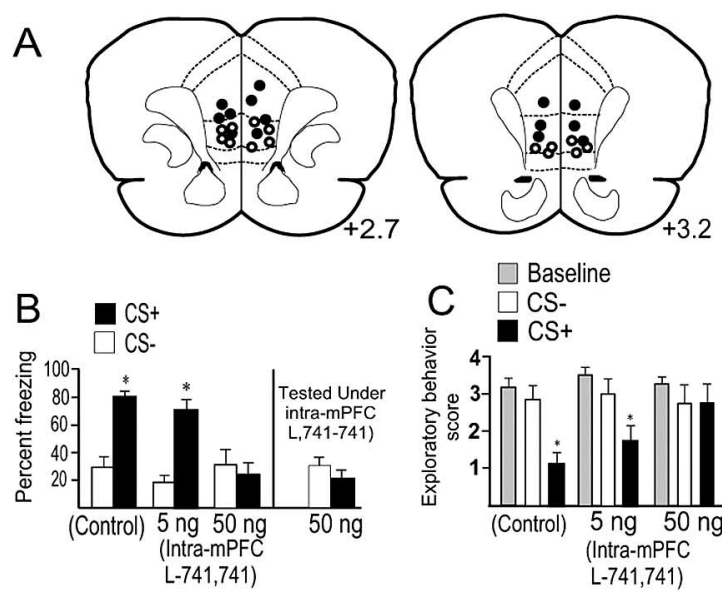

D
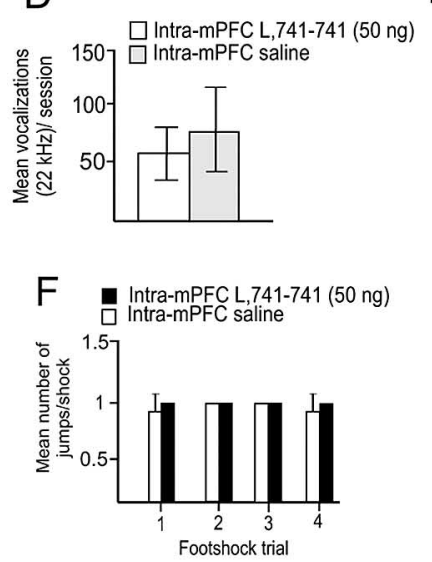

$E$
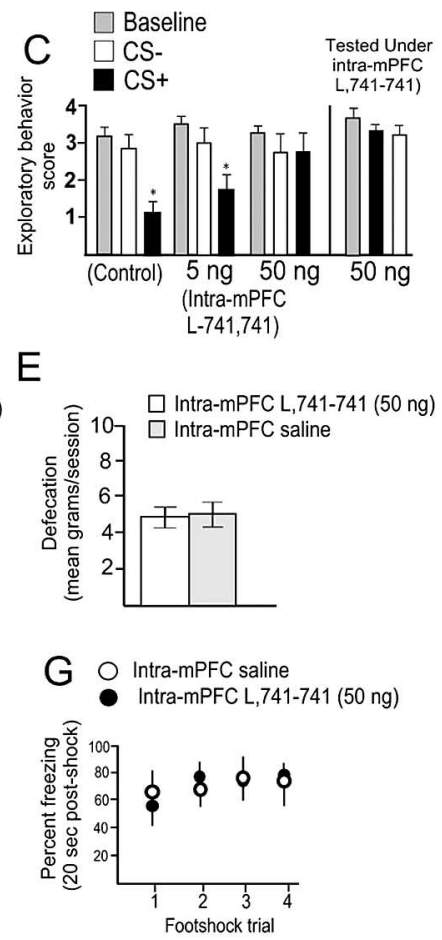

Figure 7. Intra-mPFC cannula placements for olfactory fear conditioning behavioral experiments and sensitivity indices. $A$, Bilateral injector cannula placements in the mPFC for $5 \mathrm{ng}$ (open circles) or $50 \mathrm{ng}$ (black circles) dose of the $\mathrm{DA}_{4}$ antagonist L-741,741. For behavioral studies, a subthreshold $(5 \mathrm{ng})$ and suprathreshold $(50 \mathrm{ng})$ dose of the $D_{4}$ receptor antagonist $\mathrm{L}-741,741$ was microinfused bilaterally into the $\mathrm{MPFC}$ in awake, behaving rats. $\boldsymbol{B}, \mathrm{In}$ an olfactory fear-conditioning procedure, bilateral intra-mPFC microinfusions of L-741,741 dosedependently blocked the acquisition of fear conditioning to presentations of footshock-paired odors. Both the control group $(n=6)$ and the $5 \mathrm{ng}$ dose $(n=7)$ of intra-mPFC L-741,741 group displayed significant freezing in response to presentations of the footshock-paired odor $(p<$ $0.05)$. However, this effect was blocked in animals receiving a higher dose of intra-mPFC L-741,741 $(p>0.05 ; 50 \mathrm{ng} ; n=7)$ and in animals tested under the intra-mPFC D4 antagonist cue $(n=6 ; p>$ $0.05)\left({ }^{*} p<0.05\right)$. C, Measurement of exploratory behavior in response to presentations of the $C S+$ or CS - odors revealed that in saline control rats $(n=6)$ and in rats receiving a lower dose of intra$\mathrm{mPFC} L-741,741(5 \mathrm{ng} ; n=7)$, exploratory behavior was significantly attenuated in the presence of the odor paired previously with footshock ( $p<0.05$ ). However, this suppression of exploratory behavior was blocked in rats receiving a higher dose of L-741,741 ( $p>0.05 ; 50 \mathrm{ng} ; n=7$ ) and in animals tested under the intra-mPFC $D_{4}$ antagonist $(50 \mathrm{ng})$ cue $(n=6 ; p>0.05)\left({ }^{*} p<0.05\right)$. $D$, Mean number of ultrasonic $22 \mathrm{kHz}$ vocalizations emitted during footshock trials over a total of four footshocks per session. Vocalizations did not differ significantly between saline control and intra$\mathrm{mPFC} L-741,741$ ( $50 \mathrm{ng} / 0.5 \mu \mathrm{l}$ ) experimental groups ( $p>0.05$ ). $E$, Mean amount of defecation measured in grams per footshock session over four footshocks did not differ significantly between saline control and intra-mPFC L-741,741 groups ( $p>0.05$ ). $\boldsymbol{F}$, Mean number of footshock-elicited jumps over trials did not differ significantly at any trial between saline control and intra-mPFC $L-741,741$ groups $(p>0.05)$. G, Percentage of time freezing in the 20 s postfootshockinterval across trials did not differ significantly between saline control and intra-mPFC L-741,741 groups during any trial $(p>0.05)$. Error bars represent SEM.

(i.e., after only a single conditioning trial) (Fig. 2C), which may suggest that learned associations are encoded in the amygdala and mPFC in a temporally contiguous manner. Future studies are required to more precisely determine the temporal parameters and functional interactions between the mPFC and amygdala during the encoding of emotional associative learning.
Although a specific role for DA signaling in the acquisition and encoding phases of emotional learning in the MPFC has not been demonstrated, conditioned fear learning is associated with the release of DA in the mPFC (Yoshioko et al., 1996; Pezze et al., 2003; Pezze and Feldon, 2004). Stressful and aversive stimuli strongly induce the release of DA in mPFC (Goldstein et al., 1994; Yoshioko et al., 1996). Blockade of $\mathrm{DA} \mathrm{D}_{1}$ and $\mathrm{D}_{2}$ signaling in the mPFC attenuates the expression of conditioned fear (Pezze et al., 2003; Pezze and Feldon, 2004), suggesting that DA signaling in the mPFC is an important component of emotional learning. Abnormalities in dopamine signaling are also well established neuropathological correlates of schizophrenia (O'Donnell and Grace, 1998; Grace, 2000), and functional and anatomical abnormalities within the mPFC and BLA have been observed in the brains of schizophrenia patients (Exner et al., 2004; Niu et al., 2004). Importantly, these functional disturbances in the amygdala-prefrontal pathway have been linked to the emotionally relevant sensory processing deficits observed in schizophrenia (Paradiso et al., 2003; Williams et al., 2004), and the DA $\mathrm{D}_{4}$ receptor subtype is aberrantly expressed in schizophrenia (Seeman et al., 1993; Meador-Woodruff et al., 1997; Stefanis et al., 1998). We found that systemic or bilateral blockade of DA $\mathrm{D}_{4}$ receptors directly in the mPFC blocked the acquisition of olfactory fear conditioning in fully awake, behaving animals as well as the encoding and expression of emotional learning in individual neurons of the mPFC. This is the first demonstration that blockade of DA $\mathrm{D}_{4}$ receptors during the acquisition phase of a fearconditioning procedure blocks the encoding of emotional associative learning and suggest that signaling through $\mathrm{mPFC} \mathrm{DA} \mathrm{D}_{4}$ substrates may be involved in the regulation of neuronal plasticity mechanisms and memory processes necessary for adaptive emotional learning and sensory processing. Although we found that systemic blockade of $\mathrm{D}_{4}$ receptors prevented the neuronal encoding of associative emotional learning, it is likely that $\mathrm{D}_{4}$ receptors were blocked globally in this procedure in multiple brain areas. In addition, it is difficult to generalize from neuronal phenomena in the anesthetized state to behavioral processes in fully conscious animals. To address these limitations, we performed intra-mPFC microinfusions of the $\mathrm{DA}_{4}$ antagonist in awake animals and found that the acquisition of emotional learning was completely blocked and that this effect was not caused by any confounds related to state-dependency effects. It is of particular interest that these animals had fully intact amygdalas, demonstrating that the $\mathrm{D}_{4}$ receptor substrate within the mPFC was able to override the encoding of the conditioned fear association within the BLA. Functional input from the mPFC to the amygdala also can inhibit neuronal output and emotional learning in neurons of the amygdala (Quirk et al., 2003; Rosenkranz and Grace, 2003; Milad et al., 2004), suggesting that functional regulation of emotional learning in both mPFC and amygdala can occur in ascending or descending pathways within this circuit. Our results suggest that the encoding and expression of learned associations between sensory stimuli and the emotional salience of these stimuli depend critically on the amygdala-mPFC pathway, a neural pathway that has been implicated in the motivational and sensory processing deficits observed in schizophrenia and addiction (Paradiso et al., 2003; Pezze and Feldon, 2003; Niu et al., 2004; Williams et al., 2004).

We demonstrate that a subpopulation of neurons within the mPFC receiving a functional input from the BLA can actively encode emotional learning and express these learned associations with increased bursting and neuronal activity specifically in response to stimuli paired previously with an emotionally salient 
event (footshock). Analysis of the postconditioning response patterns revealed that only $\mathrm{mPFC}$ neurons receiving BLA input increased both the percentage of bursting events and number of spikes within each burst event specifically in response to the presentation of the odor paired previously with footshock. No such differential responding was observed in non-BLA-responsive mPFC neurons that failed to demonstrate associative learning. Presently, the functions of neuronal bursting in the processing of emotionally salient information are not understood. However, our results demonstrate that medial prefrontal cortical neuronal bursting in a subpopulation of neurons receiving functional input from the BLA may represent the active encoding and/or expression of emotional learning. Neurons in this amygdala-prefrontal cortical circuit are critical for the neural encoding of learned associations between sensory stimuli and emotionally salient events and functional disturbances in this neural circuitry involving fronto-cortical $\mathrm{DA} \mathrm{D}_{4}$ receptor signaling substrates may contribute to the aberrant emotional sensory processing and associative learning observed in disorders such as schizophrenia and addiction.

\section{References}

Aggleton JP (2000) The amygdala: a functional analysis, Ed 2. New York: Oxford UP.

Antoniadis EA, McDonald RJ (1999) Discriminative fear conditioning to context expressed by multiple measures of fear in the rat. Behav Brain Res 101:1-13.

Baeg EH, Kim YB, Jang J, Kim HT, Mook-Jung I, Jung MW (2001) Fast spiking and regular spiking neural correlates of fear conditioning in the medial prefrontal cortex of the rat. Cereb Cortex 11:441-451.

Barbieri R, Quirk MC, Frank LM, Wilson MA, Brown EN (2001) Construction and analysis of non-Poisson stimulus-response models of neural spiking activity. J Neurosci Methods 105:25-37.

Ceci A, Brambilla A, Duranti P, Grauert M, Grippa N, Borsini F (1999) Effect of antipsychotic and selective dopaminergic antagonists on dopamine-induced facilitatory activity in prelimbic cortical pyramidal neurons: an in vitro study. Neuroscience 93:107-115.

Connors BW, Gutnick MJ (1990) Intrinsic firing patterns of diverse neocortical neurons. Trends Neurosci 13:365-366.

Deeprose C, Andrade J, Varma S, Edwards N (2004) Unconscious learning during surgery with propofol anesthesia. Br J Anaesth 92:171-177.

Degenetais E, Thierry AM, Glowinski J, Gioanni Y (2002) Electrophysiological properties of pyramidal neurons in the rat prefrontal cortex: an in vivo intracellular recording study. Cereb Cortex 12:1-16.

Exner C, Boucsein K, Degner D, Irle E, Weniger G (2004) Impaired emotional learning and reduced amygdala size in schizophrenia: a 3-month follow-up. Schizophr Res 71:493-503.

Garcia R, Vouimba RM, Baudry M, Thompson RF (1999) The amygdala modulates prefrontal cortex activity relative to conditioned fear. Nature 402:294-296

Goldstein LE, Rasmusson AM, Bunney BS, Roth RH (1994) The NMDA glycine site antagonist (+)-HA-966 selectively regulates conditioned stress-induced metabolic activation of the mesoprefrontal cortical dopamine but not serotonin systems: a behavioral, neuroendocrine and neurochemical study in the rat. J Neurosci 14:4937-4950.

Grace AA (2000) Gating of information flow within the limbic system and the pathophysiology of schizophrenia. Brain Res Brain Res Rev 31:330-341.

$\mathrm{Gu}$ Z, Yan Z (2004) Bidirectional regulation of $\mathrm{Ca}^{2+} /$ calmodulin dependent protein kinase II activity by dopamine D4 receptors in prefrontal cortex. Mol Pharmacol 66:948-955.

Inout M, Oomura Y, Aou S, Nishino H, Sikdar SK (1985) Reward related neuronal activity in monkey dorsolateral prefrontal cortex during feeding behavior. Brain Res 326:307-312.

Jackson ME, Homayoun H, Moghaddam B (2004) NMDA receptor hypofunction produces concomitant firing rate potentiation and burst activity reduction in the prefrontal cortex. Proc Natl Acad Sci USA 101:8467-8472.

LeDoux JE (2000) Emotion circuits in the brain. Annu Rev Neurosci 23:155-184.

Meador-Woodruff JH, Haroutunian V, Powchik P, Davidson M, Davis H,
Watson SJ (1997) Dopamine receptor transcript expression in striatum and prefrontal and occipital cortex. Focal abnormalities in orbitofrontal cortex in schizophrenia. Arch Gen Psychiatry 54:1089-1095.

Milad MR, Quirk GJ (2002) Neurons in the medial prefrontal cortex signal memory for fear extinction. Nature 420:70-74.

Milad MR, Vidal-Gonzalez I, Quirk GJ (2004) Electrical stimulation of the medial prefrontal cortex reduces conditioned fear in a temporally specific manner. Behav Neurosci 118:389-394.

Mrzljak L, Bergson C, Pappy M, Huff R, Levenson R, Goldman-Rakic PS (1996) Localization of dopamine D4 receptors in GABAergic neurons of the primate brain. Nature 381:245-248.

Nader K, Schafe GE, LeDoux JE (2000) Fear memories require protein synthesis in the amygdala for reconsolidation after retrieval. Nature 406:722-726.

Niu L, Matsui M, Zhou SY, Hagino H, Takahashi T, Yoneyama E, Kawasaki Y, Suzuki M, Seto H, Ono T, Kurachi M (2004) Volume reduction of the amygdala in patients with schizophrenia: a magnetic resonance imaging study. Psychiatry Res 132:41-51.

O’Donnell P, Grace AA (1998) Dysfunctions in multiple interrelated systems as the neurobiological bases of schizophrenic symptom clusters Schizophr Bull 24:267-283.

Ono T, Nishino H, Fukuda M, Sasaki K, Nishijo H (1984) Single neuron activity in dorsolateral prefrontal cortex of monkey during operant behavior sustained by food reward. Brain Res 311:323-332.

Paradiso S, Andreason NC, Crespo-Facorro B, O'Leary DS, Watkins GL, Boles LL, Hichwa RD (2003) Emotions in unmedicated patients with schizophrenia during evaluation with positron emission tomography. Am J Psychiatry 160:1775-1783.

Paxinos G, Watson C (1986) The rat brain in stereotaxic coordinates, Ed 2. San Diego: Academic.

Pezze MA, Feldon J (2004) Mesolimbic dopaminergic pathways in fear conditioning. Prog Neurobiol 74:301-320.

Pezze MA, Bast T, Feldon J (2003) Significance of dopamine transmission in the rat medial prefrontal cortex for conditioned fear. Cereb Cortex 13:371-380.

Quirk GJ, Likhtik E, Pelletier JG, Pare D (2003) Stimulation of medial prefrontal cortex decreases the responsiveness of central amygdala output neurons. J Neurosci 23:8800-8807.

Rosenkranz A, Grace AA (2002) Dopamine-mediated modulation of odorevoked amygdala potentials during Pavlovian conditioning. Nature 417:282-287.

Rosenkranz JA, Grace AA (2003) The prefrontal cortex regulates lateral amygdala neuronal plasticity and responses to previously conditioned stimuli. J Neurosci 23:11054-11064.

Santini E, Ge H, Pena de Ortiz S, Quirk GJ (2004) Consolidation of fear extinction requires protein synthesis in the medial prefrontal cortex. J Neurosci 24:5704-5710.

Schultz W, Dickinson A (2000) Neuronal coding of prediction errors. Annu Rev Neurosci 23:473-500.

Seeman P, Guan HC, Van Tol HH (1993) Dopamine D4 receptors are elevated in schizophrenia. Nature 365:441-445.

Shah AA, Sjovold T, Treit D (2004) Selective antagonism of medial prefrontal cortex D4 receptors decreases fear-related behavior in rats. Eur J Neurosci 19:3392-3397.

Stefanis NC, Bresnick JN, Kerwin RW, Schofield WN, McAllister G (1998) Elevation of D4 dopamine receptor mRNA in postmortem schizophrenic brain. Brain Res Mol Brain Res 53:112-119.

Tonoue T, Ashida A, Makino H, Hata H (1986) Inhibition of shock-elicited ultrasonic vocalization by opioid peptides in the rat: a psychotropic effect. Psychoneuroendocrinology 11:177-184.

Wedzony K, Chocyk A, Mackowiak M, Fijal K, Czyrak A (2000) Cortical localization of dopamine D4 receptors in the rat brain-immunocytochemical study. J Physiol Pharmacol 51:205-221.

Williams LM, Das P, Harris AWF, Liddell BB, Brammer MJ, Olivieri G, Skerrett D, Phillips ML, David AS, Peduto A, Gordon E (2004) Dysregulation of arousal and amygdala-prefrontal systems in paranoid schizophrenia. Am J Psychiatry 161:480-489.

Wong PS, Bernat E, Snodgrass and Shevrin H (2004) Event-related brain correlates of associative learning without awareness. Int J Psychophysiol 53:217-231

Yoshioko M, Matsumoto M, Togashi H, Saito H (1996) Effect of conditioned fear stress on dopamine release in the rat prefrontal cortex. Neurosci Lett 209:201-203. 